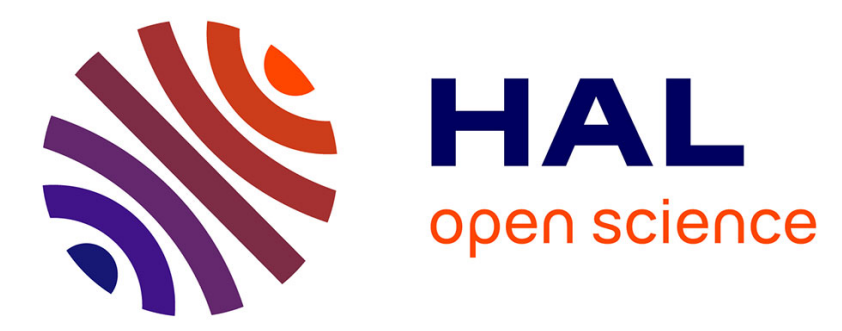

\title{
Trends in high pressure developments for new perspectives
}

Alain Largeteau, Mythili Prakasam

\section{To cite this version:}

Alain Largeteau, Mythili Prakasam. Trends in high pressure developments for new perspectives. Solid State Sciences, 2018, 80, pp.141-146. 10.1016/j.solidstatesciences.2018.04.012 . hal-01783922

\section{HAL Id: hal-01783922 \\ https://hal.science/hal-01783922}

Submitted on 2 May 2018

HAL is a multi-disciplinary open access archive for the deposit and dissemination of scientific research documents, whether they are published or not. The documents may come from teaching and research institutions in France or abroad, or from public or private research centers.
L'archive ouverte pluridisciplinaire HAL, est destinée au dépôt et à la diffusion de documents scientifiques de niveau recherche, publiés ou non, émanant des établissements d'enseignement et de recherche français ou étrangers, des laboratoires publics ou privés. 


\title{
Trends in high pressure developments for new perspectives
}

\author{
Alain Largeteau , Mythili Prakasam \\ CNRS, Univ. Bordeaux, ICMCB, UMR 5026, F-33600 Pessac, France
}

\section{a bstract}

Temperature and Pressure are two parameters in the universe, where pressure represents the largest scale in comparison to temperature. The design of high pressure equipment depends mainly on the media used which could be gas, liquid or solid and the objective could be synthesis of materials or in situ characterization. The development of new research fields requiring high pressure equipment which are currently in Bordeaux e France are based on the historical development of high pressure domain initiated by Professor Gerard DEMAZEAU and his team during the last half century, which is discussed here. The main concepts governing the effect of pressure on materials synthesis is by the combination of high pressure and high temperature which are described with apt examples. There is an upsurge in various technologies for strong development for the synthesis of materials to drive several possibilities, for example: to reach very high density to obtain optical ceramics (by conventional SPS), to diminish parameters (P, T, t) of synthesis (by HP-SPS), to sinter at low temperature thermal sensitive composition (by HyS), to consolidate porous materials (by FIP), to densify biocomposite with cold decontamination (by HHP) simultaneously, etc.

\section{Introduction}

The term Pressure was used for the first time by Blaise PASCAL in the Equilibrium Treaty of liquors [1]. Pressure became an important parameter only in the second half of 19 th century, due to the gas compression experiments leading to reach pressure in the order of 430 bar. Temperature and Pressure are the two principal parame-ters in Universe, pressure presents the largest scale in comparison to temperature. The range of pressure is very large, from approximatively $10^{30}$ bar (partial pressure in the space of hydrogen) to $10^{30} \mathrm{bar}$ (pressure in the center of a neutron-star). More than $90 \%$ of materials in universe is subjected to a pressure greater than $10^{6}$ bar. Then, 1 bar on the earth is like an exceptional condition. The pressure on Earth, can reach bottom of abyssal pits to 1100 bar (110 MPa) and probably 3.7 million bar (370 GPa) in the center of Earth [2].

The use of pressure parameter is important for exploring various phenomena in chemistry, physics, biology and other domains. Consequently this knowledge is very useful for development of industrial processes to fabricate materials for various applications. Development of pressure equipment is quite recent in comparison

\footnotetext{
* Corresponding author.

E-mail address: alain.largeteau@u-bordeaux.fr (A. Largeteau).
}

to temperature because research in high pressure needs interdis-ciplinary knowledge such as mechanics (to resist pressure), chemistry (to avoid corrosion), physics (to measure pressure and temperature), etc. Materials fabricated by application of pressure are comparatively less developed than those fabricated by appli-cation of temperature. The design of high pressure equipment de-pends mainly on the media used, which could be gas, liquid or solid and also depends on the compressibility of this pressure trans-mitter. The objectives of such equipment for laboratories is either for synthesis of materials or in situ characterization and are mainly employed for synthesis in industrial applications.

This article presents the development of pressure technology a thematic also initiated by Prof. Gerard DEMAZEAU and his team at different periods of his career, during the last half century. Professor

Gerard DEMAZEAU (GD) started his work on the effect of pressure in Materials Chemistry, followed by Materials Science, Environ-mental science and finally in Biosciences. After his retirement, he created a company (HPBioTECH) in 2010 with principal application of pressure in Biosciences such as in Food, Pharmaceuticals, Cos-metics and Health.

Formerly, LCS and currently known by the name ICMCB, has acquired variety of pressure related technical facilities, ranging from autoclaves for reactions in fluids (liquids and gases), a Belt-type apparatus, pilots equipment for high-pressure Biosciences treatment. The following sections will explain in detail about the 
various domains developed by Professor Gerard DEMAZEAU and his team.

\section{High pressure technologies development done by Professor Gerard DEMAZEAU and his team}

In the beginning of the years 1970s, the studies on the stabili-zation of unusual oxidation states of transition metals such $\mathrm{Co}^{3} \mathrm{p}, \mathrm{Ni}^{3 \mathrm{p}}$ and $\mathrm{Cu}^{3 \mathrm{p}}$ led to the development of HP equipment under solid phase with Belt type apparatus by compression of solid phase and gas phase by direct compression of fluid; both for oxidation under high pressure [3].

Regarding gases which are extremely compressible, the HP equipment needs several compression stages with the first stage for compression by pump from gas tube (at least at $10 \mathrm{MPa}$ ) to reach up to $100 \mathrm{MPa}$. The second stage called "multiplier" is a piston cylinder by using compression of oil which is the liquid transmitter media. The significance of this equipment, designed in Bordeaux, is based on the use of chloro-trifluoro-ethylene polymer (PCTFE) as liquid transmitter which doesn't react with oxygen and polymer seals that are stable under oxygen pressure and compatible with PCTFE. The pressure-vessel in which gas pressure could reach $500 \mathrm{MPa}$ at ambient temperature, could be used at $900 \mathrm{C}$ at $50 \mathrm{MPa}$ for Nickel superalloy by external heating in conventional furnace. Due to the confined energy induced by high compressibility of gas and by using oxygen which impeach the use of grease (generally easily oxidizing), it is mandatory to apply specific protections and safety rules and to use only small volume $\left(30 \mathrm{~cm}^{3}\right)$ of vessel [3].

Regarding solid phase media for which compressibility is very small, the belt type apparatus could reach $7 \mathrm{GPa}$ and $2000 \mathrm{C}$ simultaneously in a volume close to $1 \mathrm{~cm}^{3}$. This Belt system was designed by Mr CONTRE in CEA constituted of two opposite anvils and one chamber all made of tungsten carbide, derivated from the Bridgman system [4]. The pressure transmitter media is made of natural rock called Pyrophyllite (aluminum silicate hydroxide) which constitute the HP-cell. By the fact of experiments are done without thermocouple due to the very small volume available in-side the HPcell, temperature is calibrated at constant pressure with thermocouple corresponding to the electric power input in the micro-furnace made of graphite tube inside the HP-cell to obtain abacus form T $1 / 4 \mathrm{f}$ (Power). Pressure can't be measured by pressure sensor like for fluids, hence calibration at ambient temperature with respect to the force applied on the Belt-type appa-ratus by the hydraulic press is necessary to obtain abacus $\mathrm{P} 1 / 4 \mathrm{f}$ (Force) by using pressure calibrants. These pressure calibrants $(\mathrm{Bi}, \mathrm{Ba}$ and $\mathrm{Tl})$ present allotropic transition inducing a great variation of electrical resistivity measured by in situ electric measurement. The originality of work done for oxidizing under high pressure is to use potassium chloride $\left(\mathrm{KClO}_{3}\right)$ inside the mixture of starting powder, which decompose with temperature following the reaction: $\mathrm{KClO}_{3}$

/ $\mathrm{KCl} \mathrm{p} 3 / 2 \mathrm{O}_{2}$ producing oxygen pressure. $\mathrm{KCl}$ which doesn't react with the most of part of precursors used, and could be removed easily by washing in water [3].

In the beginning of 1980s, new axe of research based on liquid phase under hydrothermal conditions with oxidizing solutions to generate micro-crystallized $\mathrm{CrO}_{2}$ powder for magnetic recording applications [5] was developed. This development for liquid phase used the same design of pressurevessel as that of gas pressure, only the nature of alloy employed was different depending on the corrosion by the nature of liquid used as pressure transmitter with approximatively the same range of $\mathrm{P}$ and $\mathrm{T}$ ( $900 \mathrm{C} / 50 \mathrm{MPa})$. HP equipment for liquid needs only one compression stage because liquid is less compressible than gas because compressibility of water is close than $15 \%$ at 1 GPa [6]; consequently the volume of vessel could be larger than for gases because it is less dangerous.
Pressure could be also produced by thermal expansion of the fluid in the closed system, called autogenous pressure according to the abacus of Kennedy [7].

Concerning the pressure-vessel which is a one-eyed cylinder, the combination of pressure and temperature limits the usage of polymer. The art is the selection of the appropriate metal for the obturator alloy, less hard than the vessel alloy which is a Nickel superalloy; both alloys are selected to be compatible with pressure and temperature of synthesis. It is easier to remodel the obturator when the plastic deformation is too important. By adjusting precisely the tightening of screws, the leak-proof of pressure-vessel is based on the small elastic deformation at the linear contact of the conic male part of obturator on the conic female part of vessel by a little difference of angle (2). The screws are screwed with dyna-mometric wrench to obtain leak-proof by elastic deformation of the obturator alloy and to avoid plastic deformation. The number of screws depends of the combination of pressure/diameter of vessel. The fluid could be gases (Oxygen, Nitrogen, Argon and Carbon di-oxide) and liquids (aqueous solutions, hydrogen fluoride, liquid ammonia, alcohol and hydrazine).

On the same domain of hydrothermal synthesis of crystallites ( $\mathrm{HyCr}$ ), a new design of equipment done in Bordeaux was to syn-thetize $\mathrm{MoO}_{2}$ in the beginning of 2000s where the pressure-vessel is not heated by Joule effect with conventional furnace but by mi-crowave put inside the pressure-vessel filled with water $[8,9]$. The objective of such equipment was to heating faster than Joule effect without heating the vessel and thus diminishing the size of particles synthetized inside the pressureevessel $\left(100 \mathrm{~cm}^{3} / 400 \mathrm{MPa} / 700 \mathrm{C}\right)$. The innovation of such equipment was to use single crys-tals of Sapphire as window-obturator on both faces of pressure vessel (not one-eyed) to be transparent to the microwave from power generators at $2.45 \mathrm{GHz}$.

In the middle of 1990s, new thematic on the hydrothermal crystal growth (HyCG) led to the design of new equipment in Bordeaux [10]. Usually, the conventional single crystals growth processes involves high temperature at ambient pressure. This conventional route doesn't allow the fabrication of single crystals for composition which presents allotropic transformation such as a-Quartz $\mathrm{SiO}_{2}$. The principle of HyCG in large volume $\left(\begin{array}{ll}1.5 & 1\end{array}\right)$ led to the development of furnace with gradient of temperature inside the vessel with a design corresponding at Length/diam z 12 favorizing the transfer of species in the fluid (Hydrothermal for aqueous solution or Solvothermal for non-aqueous solution such as nitride) from the hot (bottom of vessel) to the cold (top of vessel) zone. This specific equipment (450 C/350 MPa) based on steels alloys designed in laboratory for large volume centimetric single crystals by using sodium hydroxide solvent. An innovative easy closing/opening system, with hydraulic cylinder without any screws, opposes a force contrary to the force crated by the fluid in the obturator. Similar precaution is also necessary in the selection of the alloys constituting obturator and vessel.

In the same period of middle of 1990s, the thematic regarding the effect of pressure in Biosciences allowed to develop a special equipment for food processing. This equipment designed in Bordeaux, used large volume of pressure-vessel $(0,81)$ with pump for direct compression of fluid (700 MPa) inside a pressure-vessel with innovative easily closing/opening system by using hydraulic cylinder without any screws [11]. The cooperation with French company Framatome allowed the building of the largest volume of vessel with the high level of pressure $(31 / 800 \mathrm{MPa} / 20 \mathrm{C})$ by decreasing the volume based on the translation of piston inside the vessel, unique in the world for its specification [12]. The solution to allow a mobile piston (diameter $120 \mathrm{~mm}$ ) without any leak is based on the use of polymer (Polyurethane with 90 shores) assembled with a metallic ring $(\mathrm{Cu}-\mathrm{Be})$ which presents high mechanical 
performance without corrosion in aqueous solution. These new thematic on food processes lead to the design of specific packaging to preserve the food from contamination by the pressure trans-mitter media surrounding the sample during the high hydrostatic pressure (HHP) process [13]. This development is beneficial even for today in HHP process on Bioscience, but also in materials sci-ences for the densification of green body done by CIP (Cold Isostatic Pressure). In fact, the material constituting the package has to be flexible, thermosealable, waterproof and compatible with pressure transmitter which could be pure water, oil for ambient temperature or glycol, silicone for negative temperature.

On the same thematic of Bioscience, for bio-separation of antigen/antibody, a semi-continuous equipment $\left(20 \mathrm{~cm}^{3} / 400 \mathrm{MPa} / 4 \mathrm{C}\right)$ constituted of one mobile pressure-vessel between two plates of obturator allows three positions: filling, HP treatment, emptying [14]. A cartridge filled by biomolecules is placed inside the pressure-vessel before to start the HP process for bio-separation. The movement of the pressure-vessel is done by electric motor monitored by computer. The sealing is assumed by nitrile O-ring placed in an O-ring space on both surface (top and bottom) of the vessel which presents two opening (not one-eyed). The first posi-tion corresponds to the filling of vessel by the cartridge. The second position corresponds to the HHP process of the cartridge inside of the vessel with the help of hydraulic cylinder to avoid leak and a pump to reach pressure for the HP bio-separation treatment. The third positon corresponds to the ejection of the cartridge with biomolecule after bio-separation.

The studies demonstrated on micro-organisms the importance of the pressure rate for compression and decompression. This effect was applied on the decontamination of Virus (VIH, measles) by using a new design of compact equipment. This equipment was placed in the P3 laboratory of Bordeaux University Victor Segalen because of pathogens studied. This equipment is capable of reaching $400 \mathrm{MPa}$ with a very high rate of compression and decompression $(>50 \mathrm{MPa} / \mathrm{s})$ is possible by using a manual pump with a small volume (10 $\mathrm{ml})$ of pressureevessel [15].

Professor Gerard DEMAZEAU felt larges potentialities in this domain to promote the interest of Pressure for Bio-applications by the creation of HPBioTECH in 2010. The strong knowledge of Pro-fessor Gerard DEMAZEAU allowed to promote several axes with team such as by using High Hydrostatic Pressure (HHP) processes done up to $500 \mathrm{MPa}$ for temperature below $80 \mathrm{C}$ :

- Food: microbial decontamination of foods while preserving its nutritional and sensorial properties (Pascalization: cold decon-tamination) and modification of the texture (texturation),

- Cosmetics: microbial decontamination (Pascalization), extrac-tion of active molecules, stabilization of novel textures (gelation phenomena) and encapsulation of components (shelling: con-trolling the release of the active components).

- Health: microbial safety (Pascalization), induction of a specific property (elaboration of vaccines), dissociation of molecular complexes (antigen/antibody), control of the kinetic of libera-tion for an active molecule from implants, extraction (peptides, proteins, active components) and de-cellurization (to eliminate the cells of miscellaneous tissues).

\section{High pressure technologies development in the path of Prof. Gerard Demazeau and his team}

This section presents three examples of technical developments currently in progress based on the past experiences using high pressure domain at ICMCB.

The examples given below presents various possibilities:
- to reach very high density for obtaining optical ceramics (by conventional SPS),

- to diminish parameters (P, T, t) of synthesis (by HP-SPS),

- to sinter at low temperature thermal sensitive composition (by HyS),

- to consolidate porous materials (by FIP) and biocomposite with cold decontamination (by HHP) simultaneously.

\subsection{Spark plasma sintering: Conventional SPS and HP-SPS}

Spark Plasma Sintering (SPS) developed in 1966 [16]. Proposed an innovative process under low pressure $100 \mathrm{MPa}$ limited by the use of graphite mold (cylinder with 2 mobile pistons). This original process based on the combination of pulsed electric current and low uniaxial force improves the material processing by thermal process. This pressure equipment under solid pressure transmitter allows to accelerate chemical reaction generally used for sintering such as: to diminish sintering duration and diminish sintering temperature; both effects are beneficial to limit grains growth and then to obtain nano-sized ceramics with a little content of porosity. The SPS (Dr Sinter e Fuji - 515-S) with maximum force of 5 tons, acquired in 2010 at ICMCB allowed to demonstrate this effect on the manufacturing of opto-ceramic where porosities are not accepetd and to design specific mold to obtained functionally graded mate-rials by electromigration [17e21]. Detailed information on this equipment which is very well documented in the literature will not be discussed here.

In 2017, a home designed equipment (Fig. 1) based on this combination of pressure with pulsed electric current (SCM-3000-Fuji) at very high pressure allowed to reach $6 \mathrm{GPa}$ at $1800 \mathrm{C}$ where the mold in graphite is replaced by Belt-type apparatus [22] with the help of maximum force of 1000 tons.

This unique equipment (HP-SPS) opens a new domain of manufacturing (densification, sintering and consolidation) with the benefit of very high pressure to synthesize materials with same objectives as that for conventional SPS (decreasing of the sintering temperature, shortening of the duration of sintering, enabling the limitation on the formation of porosity, acceleration of densifica-tion process, etc.) with additive benefits such as for compositions which present:

- Low chemical reactivity such as refractory materials (carbide, nitride, boride), pressure acts as a driving force in addition to temperature [22].

- Stabilization of densest phase by pressure: c-C (diamond), c-SiC (moissanite), c-BN, etc.

- Stabilization of phase under temperature above than thermal points (decomposition, melting) allowing chemical reaction at temperature higher than this thermal transformation, pressure reinforces the bond of chemical structures by compression effect leads to a lowering of the volume and consequently to decrease the interatomic distances.

- Decreasing the temperature of phase transition for sintering the densest phase at lower temperature

These examples given show the great interest of this new technology improvement based on solid phase pressure trans-mitter deviated from the chemical process based on conventional SPS.

\subsection{Hydrothermal sintering (HyS)}

The Hot Pressing in hydrothermal condition defined in 1972 [23] proposes a deviation of conventional hot pressing by adding water 


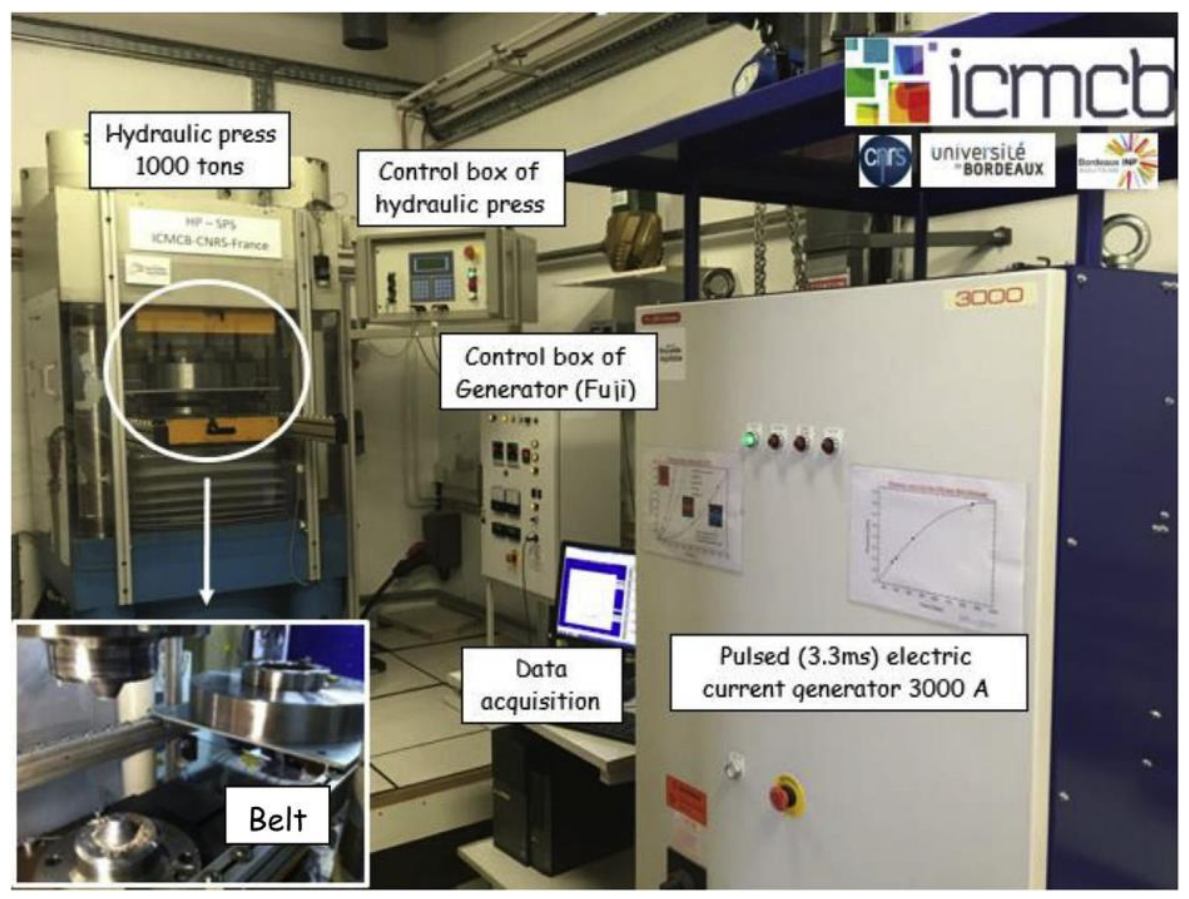

Fig. 1. HP-SPS with Belt-type equipment.

in the sample. This equipment using liquid pressure transmitter doesn't permit to sinter at temperature higher than $370 \mathrm{C} / 220 \mathrm{MPa}$ because of the limitation of the use of polymer to assure leak-proof under pressure. Our home designed (Fig. 2) Hydrothermal sintering (HyS) equipment permits to reach $500 \mathrm{C} / 350$ MPa by the specific design to guaranty the axial mobility of both pistons inside the pressure-vessel under temperature above than thermal decompo-sition of polymer seals. Knowing that water presents critical points given by Tc $1 / 4374 \mathrm{C} / \mathrm{Pc} 1 / 422 \mathrm{MPa}$, we are able to do experiments for manufacturing materials under supercritical fluid (SCF) while the others in literature has to stay in undercritical fluid (UCF) area.

This HyS method objectives are to densify, consolidate or sinter materials at lower temperature than usual sintering processes which use high temperatures. This process is based on the disso-lution - precipitation phenomena of the raw powder by the solvent content inside the sample which is a mixture powder/solvent

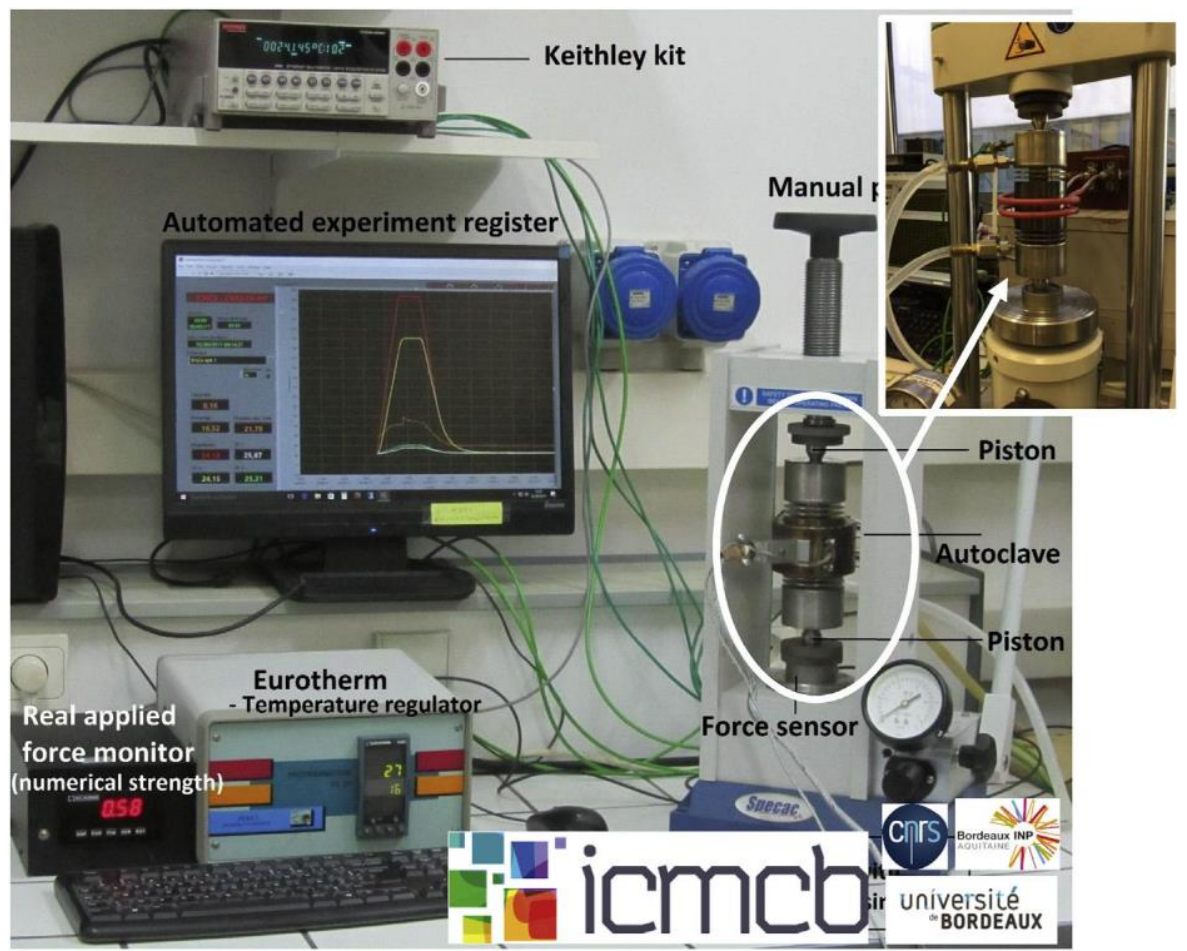

Fig. 2. HyS equipment with heating collar and heater inductive in inset. 
(water only or with mineralizer $(\mathrm{NaOH}, \mathrm{KOH}$, etc.) to increase sol-ubilization of grains) and not on the diffusion phenomena like in conventional sintering technologies. The hydrothermal process is a deviation of chemical principle of hydrothermal crystal growth (HyCG) used for synthesis of single crystals of a-

Quartz $\mathrm{SiO}_{2}$. Hy-drothermal conditions allows chemical reaction at temperature lower than in solid state reaction by the effect of undercritical or supercritical state of the fluid. HyS is a combination of:

- Two pressure: one is pressure created by external uniaxial force (higher and localized at grains contact) imposed by external hydraulic press and the second is created by autogenous hy-drostatic pressure (lower and isostatic surrounding the grains) created by the expansion of solvent inside the mixture of sam-ple, which contains powder and liquid water, following the Kennedy's abacus [24]. The gradient of pressure between grain contacts and free spaces between grains partially full of water in undercritical (UCF) or supercritical (SCF) state depending on temperature, acting like osmotic pressure effect. The trans-portation of species from high stress contact point to the less stress contact point to initiate the neck formation by precipi-tation due to the supersaturation of solvent by species in such conditions of pressure.

- One temperature T: determine the state of fluid (SCF, UCF) for driving the dissolution regarding the composition of solid phase (metal, ceramics,.) and to transport species in the fluid.

- Solvent: determine the dissolution/precipitation process and permits the transport of species by osmotic effect due to the saturation of species at pressure of contact which becomes supersatuared by species under lower pressure inside the free spaces.

The motion of species dissolved in solvent is driven by gradient of pressure (in contrary of hydrothermal crystal growth which is driven by gradient of T), species diffuse along the grain boundary inside fluid phase. The precipitation will occur in the zone less stressed (in the free space between grains) by supersaturation of solvent, saturation depending on pressure-temperature couple. Duration allows the formation of necks starting at the closest area of grains contact (higher stress) in the free spaces (lower stress) full of water in $\mathrm{UCF} / \mathrm{SCF}$ state allows shrinkage up to the complete sintering process

This HyS process allows sintering at lower temperature than usual and also to drive the phase transformation in situ by disso-lution of amorphous phase and precipitation of crystalized phase depending on the parameters $\mathrm{P}$ and $\mathrm{T}$ $[25,26]$.

The original HyS process allows the possibility to obtain ce-ramics of aQuartz $\mathrm{SiO}_{2}$ with amorphous precursors of silica at lower temperature than phase transition temperature of a-b Quartz $\mathrm{SiO}_{2}$ [27].

This innovative equipment HyS allows to manufacture materials for: hydrated composition (ex: Hap), porous or dense microstruc-ture, low chemical reactivity under $500 \mathrm{C}$, low structural phase (ex: TiO2-anatase), phase transformation existing only under $500 \mathrm{C}$ but under pressure (ex: a-Quartz $\mathrm{SiO}_{2}$ ), etc.

The influence of heating rate parameter could allow to control the formation of neck and to favorize nano-structure by limitation of grains growth. An inductive heating system allows to reach $450 \mathrm{C}$ in $30 \mathrm{~min}$ inside the pressure vessel in comparison with the previous heating collar system which needs at least $90 \mathrm{~min}$ to reach the optimal target temperature.

These examples given show the great interest of this new technology improvement based on liquid phase pressure trans-mitter deviated from the chemical process based on conventional HyCG.

\subsection{Freeze isostatic consolidation (FIP)}

Another combination of pressure and temperature, in this case for applications in Biosciences was developed at temperature below than $0 \mathrm{C}$ to manufacture porous structure of biomaterials. This innovative equipment home-designed, called Freeze Isostatic Pressure (FIP) could work in the range $40 \mathrm{C} / 400 \mathrm{MPa}$. FIP allows to drive the ice crystals nucleation/growing of water, used as template inside the mixture of sample which contains powder and liquid water. Water is easily eliminated by return at ambient conditions.

The phase diagram of water shows the possibility to keep liquid water at around $20 \mathrm{C}$ under $200 \mathrm{MPa}$ and the existing of 4 different crystallized chemical structure of ice [28]. The objective by using the parameters $\mathrm{P}$ and $\mathrm{T}$, is to select the path for selecting the crystals Ih, II, III and V. The characteristics of such ices are following:

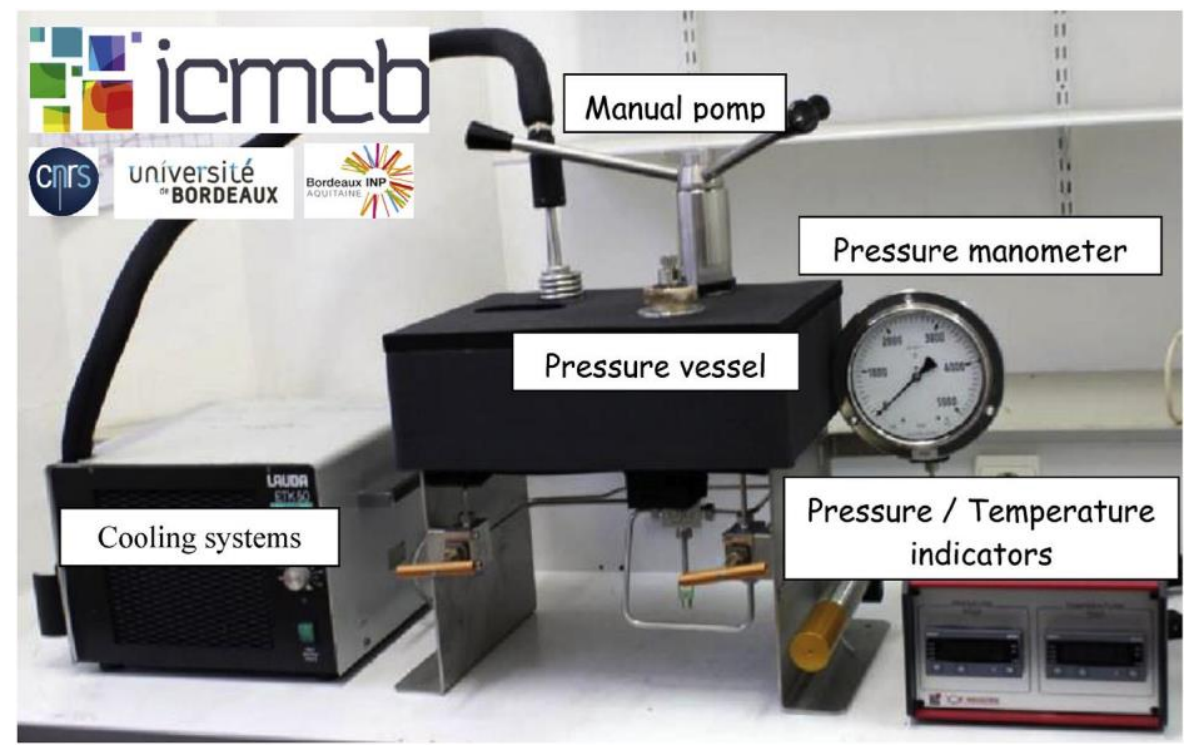

Fig. 3. FIP equipment. 
Ice Ih: Hexagonal (0.92 g.cm-3), Ice II: Rhombohedra (1.17 g.cm-3), Ice III: Tetragonal (1.14 g.cm-3), Ice V: Monoclinic (1.23 g.cm-3). The rate of compression/decompression and freezing/thawing are determining for the final size of porosities initiated by crystalliza-tion. At the contact point between grains, the dissolution-precipitation into the interfacial water film occurs and could be also activated by solid-state welding processes (cold-welding) process to obtain a monoliths well consolidated. The dissolution localized at grains contact favored by high stress contact point acts like the dissolutioneprecipitation processes expected for HyS process, explained previously where temperature enhances this phenomena. The transportation of species along the grain bound-ary in the less stress contact point leads to a precipitation on par-ticle surface and initiate the neck formation in the free paces between grains.

Various works done on cold contamination by High Hydrostatic Pressure (HHP) demonstrated the benefit of pressure for decon-tamination of microorganisms but also at sub-zero domain [29]. This technique opens a vast options for porous ceramics that are currently employed for various applications.

Our innovative equipment (Fig. 3) allows obtaining porous structure of biocomposites (inorganic structure with thermo-sensible polymer or therapeutic molecules as an example) with as second effect a decontamination at low temperature, called cold decontamination (also called Pascalization) by HPP process, [30].

\section{Conclusion}

We tried to demonstrate, in this article dedicated to Prof. Gerard DEMAZEAU, how the combination of pressure and temperature could help in the development of new materials with specific properties based on innovative design of equipment. We have discussed a few of the important technological developments that were done and is currently being developed from/by domains

developed by Prof. Gerard DEMAZEAU. Phase diagram is the base of the thinking for improving the scientific research on materials to be manufactured. The complementary of knowledge on engineering (mechanics, physics and chemistry) allows to validate the concept based on High Pressure science. Pressure is currently turning into a beautiful tool for the material science domain and will continu-ously keep on developing forever to explore its vast options.

We thank Prof. Gerard DEMAZEAU who shared since last 30 years about the knowledge on High Pressure effect in various thematic of Science (materials chemistry, materials science, bio-sciences) and for his contribution to introduce new processes for driving pressure and temperature parameters regarding the phase diagram.

\section{References}

[1] B. Pascal, in: G. Desprez (Ed.), Traite de l'equilibre des liqueurs et de la pesanteur de la masse de l'air, 1663. Paris.

[2] P. Richet, Une Courte Histoire de la Pression, in: J.C. Chervin, J. Peyronneau (Eds.), La Pression : un Outil Pour les Sciences, Editions du CNRS, 2003.

[3] G. Demazeau, Theses es Science, Bordeaux University, 1973.
[4] M. Contre, Thesis Bordeaux University, 1985.

[5] G. Demazeau, Generation of high oxygen pressure by the decomposition of oxidizing acids or $\mathrm{NH} 4 \mathrm{ClO} 4$ under hydrothermal conditions: application to the preparation of $\mathrm{CrO}_{2}$, High. Pres Sci. Technol. 1 (1980) 572e575.

[6] Bridgman, Water in the liquid in the 5 solid forms under pressure, Proc. Am. Acad. Arts Sci. 47 (13) (1912), 441e558.

[7] Kennedy, Pressure Volume Temperature Relations in water at elevated tem-perature and pressure, Am. J. Sci. 248 (1950) 540e564.

[8] S. Oree, Thesis Bordeaux University, 1997.

[9] A. Largeteau, S. Oree, C.L. Marzar, G. Demazeau, Microwave heating in high pressure reaction vessels, High Pres. Res. 20 (2001) 281 e288.

[10] Hydrothermal crystal growth of a-quartz: new specificities correlated to applications, in: G. Demazeau, F. Lafon (Eds.), Journal de Physique IV vol. 4, 1994, pp. $13 \mathrm{e} 18$.

[11] C. Tonello, P. Wurtz, A. Largeteau, F. Jolibert, A. Deschamps, A. Ducastaing, G. Demazeau, Recent developments in the use of high hydrostatic pressures in food processing, High Pres. Res. 12 (1994) 205 e213.

[12] Felix Sancho, Yann Lambert, Gerard Demazeau, Alain Largeteau, Jean-Marie Bouvier, Jean-Francois Narbonne, Effect of ultra-high hydrostatic pressure on hydrosoluble vitamins, J. Food Eng. 39 (1999) 247e253.

[13] Y. Lambert, G. Demazeau, A. Largeteau, J.M. Bouvier, S. Laborde-Croubit, M. Cabannes, Packaging for high-pressure treatment in the food industry, Packag. Technol. Sci. 13 (2000) $63 \mathrm{e} 71$.

[14] G. Demazeau, A. Largeteau, P.Lemay, Bioreacteur Hyperbar fonctionnant en mode SemiContinu, in: Genie des procedes biotechnologiques, vol. 1, 2000, pp. $21 \mathrm{e} 24$.

[15] N. Rivalain, Thesis Bordeaux University, 2009.

[16] Inoue, Electric Discharge Sintering, US Patent 3241 956, 1966. Apparatus for electrically sintering discrete bodies e US Patent 3250 892(1966).

[17] M. Prakasam, Fr Weill, E. Lebraud, O. Viraphong, S. Buffiere, A. Largeteau, Densification of 8Y-Tetragonal-Stabilized Zirconia opto-ceramics with improved optical properties by Y segregation, Appl. Ceram. Technol. 13 (5) (2016) 904e911.

[18] M. Prakasam, D. Michau, O. Viraphong, A. Largeteau, Optimal sintering pa-rameters for $\mathrm{Al} 2 \mathrm{O} 3$ optoceramics with high transparency by spark plasma sintering, Adv. Appl. Ceram. Struct. Funct. Bioceram. 115 (6) (2016) $333 \mathrm{e} 341$.

[19] M. Prakasam, O. Viraphong, D. Michau, A. Largeteau, Critical parameters to obtain Yb3p doped Lu2O3 and ZnO transparent ceramics, Ceram. Int. 40 (1) (2014) 1859 e1864.

[20] M. Prakasam, O. Viraphong, D. Michau, K. Shimamura, A. Largeteau, Yb3p doped Lu2O3 transparent ceramics by spark plasma sintering, Ceram. Int. 39 (2) (2013) 1307e1313.

[21] F. Balima, O. Viraphong, A. Dourfaye, H. Etcheberry, A. Largeteau, Functionally graded cutting tools obtained by SPS electromigration, under-review.

[22] F. Balima, F. Bellin, D. Michau, O. Viraphong, A. Poulon-Quintin, U.-C. Chung, A. Dourfaye, A. Largeteau, High pressure pulsed electric current activated equipment (HPSPS) for material processing, Mater. Des. 139 (2018) 541e548.

[23] D.M. Roy, G.R. Gouda, A. Bobrowsky, Very high strength cement pastes pre-pared by hot pressing and other high pressure techniques, Cement Concr. Res. 2 (1972) 349e366.

[24] Kennedy, Pressure Volume Temperature Relations in water at elevated tem-perature and pressure, Am. J. Sci. 248 (1950) 540e564.

[25] A. Ndayishimiye, A. Largeteau, S. Mornet, M. Duttine, M.A. Dourges, D. Denux, M. Verdier, M. Goune, T. Herisson de Beauvoir, C. Elissalde, G. Goglio, Hy-drothermal sintering for densification of silica. Evidence for the role of water, J. Eur. Ceram. Soc. 38 (4) (2018) $1860 \mathrm{e} 1870$.

[26] A. Ndayishimiye, S. Buffiere, M.A. Dourges, A. Largeteau, M. Prakasam, S. Mornet, O. Kaman, J. Zdeněk, J. Hejtmanek, G. Goglio, Design of 0-3 type nanocomposites using hydrothermal sintering, Scripta Mater. 148 (2018) $15 \mathrm{e} 19$.

[27] A. Ndayishimiye, A. Largeteau, M. Prakasam, S. Pechev, M.-A. Dourges, G. Goglio, Low temperature hydrothermal sintering process for the quasi-complete densification of nanometric a-quartz, Scripta Mater. 145 (2018) $118 \mathrm{e} 121$.

[28] Makita, Application of high pressure and thermophysical properties of water to biotechnology, Fluid Phase Equil. 76 (1992) 87e95.

[29] S. Buzrul, Thesis Bordeaux University, 2006.

[30] A. Largeteau, M. Prakasam, Procede de fabrication d'un materiau mono-lithique poreux, France Brevet FR 3038896. 2017-01-20. 28; International Patent WO 2017013339 (201701-26). 